Bärbel Schnegg

Die Inschriften zu den Ludi saeculares 



\author{
Bärbel Schnegg
}

\title{
Die Inschriften zu den Ludi saeculares
}

\author{
Acta ludorum saecularium
}

Unter Mitarbeit von Wolfram Schneider-Lastin

Mit einem Beitrag zur Prosopografie von François Chausson 
Die Open-Access-Version sowie die Druckvorstufe dieser Publikation wurden vom Schweizerischen Nationalfonds zur Förderung der wissenschaftlichen Forschung unterstützt.

\title{
FN WNF
}

\author{
SCHWEIZERISCHER NATIONALFONDS \\ ZUR FÖRDERUNG DER WISSENSCHAFTLICHEN FORSCHUNG
}

\section{(cc) BY-NC-ND}

Dieses Werk ist lizenziert unter der Creative Commons Attribution-NonCommercial-

NoDerivatives 4.0 International Lizenz. Weitere Informationen finden Sie unter http://creativecommons.org/licenses/by-nc-nd/4.0/.

ISBN 978-3-11-061331-5

e-ISBN (PDF) 978-3-11-060783-3

DOI https://doi.org/10.1515/9783110607833

Library of Congress Control Number: 2020934239

Bibliografische Information der Deutschen Nationalbibliothek

Die Deutsche Nationalbibliothek verzeichnet diese Publikation in der Deutschen Nationalbibliografie; detaillierte bibliografische Daten sind im Internet über http://dnb.dnb.de abrufbar.

(C) 2020 Bärbel Schnegg, publiziert von Walter de Gruyter GmbH, Berlin/Boston Dieses Buch ist als Open-Access-Publikation verfügbar über www.degruyter.com.

Umschlagabbildung: Römische Bronzemünze unter Kaiser Domitian (siehe auch Anhang Abb. 11)

(C) bpk/Münzkabinett, SMB/Lutz-Jürgen Lübke (Lübke und Wiedemann)

Satz: swissedit, Zürich

Druck und Bindung: CPI books GmbH, Leck

www.degruyter.com 